\title{
Modeling and Oil Contamination Influence Control of a Vehicle Mounted and Unbalanced Barrel Pitching System
}

\author{
Yuanbo Chu (iD) \\ School of Photoelectric Engineering, Xi'an Technological University, Xi'an 710021, China \\ Correspondence should be addressed to Yuanbo Chu; chuyuanbo528@163.com
}

Received 2 April 2019; Revised 14 July 2019; Accepted 10 September 2019; Published 1 October 2019

Academic Editor: Mario Terzo

Copyright (c) 2019 Yuanbo Chu. This is an open access article distributed under the Creative Commons Attribution License, which permits unrestricted use, distribution, and reproduction in any medium, provided the original work is properly cited.

\begin{abstract}
The vehicle mounted and unbalanced barrel pitching system is a typical kind of high precision electrohydraulic servo system. The key to system control is not only to overcome the influence of external interference such as unbalanced torque and road fluctuation, but also to suppress the influence of internal parameters' change induced by oil contamination. Firstly, the overall model of barrel pitching system is established and its sensitivity analysis is conducted, and then the correction link and the pressure difference feedback loop are respectively designed to suppress the influence of unbalanced torque and road fluctuation. Secondly, the influence of oil contamination is categorized and the core decay parameters are determined, and then the fractional order fuzzy PID controller is designed. Finally, the simulation model of MATLAB/Simulink is built and the system simulation is carried out. The results show when the given angle is fixed on $25^{\circ}$, the setting time is reduced to $0.2 \mathrm{~s}$, and the maximum steady state error is only $0.000132 \mathrm{rad}$. Thus, the presented method is effective for barrel pitching system's control, and the service life of the equipment can be prolonged under the same required accuracy.
\end{abstract}

\section{Introduction}

In order to improve the shooting accuracy, the tank is usually equipped with an artillery stabilizer that can effectively isolate the effect of vehicle motion, as shown in Figure 1 . The artillery stabilizer, also known as gun control system, can make the barrel unaffected by the pitching and steering of vehicle and then ensure the tank shooting during marching. It can also control the position of the barrel in the vertical direction and the horizontal direction so as to precisely aim [1], in which the vertical pitching motion attracts more attention due to the greater effect of road fluctuation.

The electrohydraulic servo system is more adopted for stability and turnover of the barrel, which has the advantages of large power to weight ratio, fast response, and high control precision. However, the outstanding weakness of this system is its low antipollution capability. According to authoritative statistics, $70 \%-80 \%$ of the hydraulic faults are caused by oil contamination. Also the electrohydraulic servo system has many uncertainties such as external interference, which seriously restricts the reaction speed and control precision $[2,3]$.

Specific to the barrel pitching system, external interference such as unbalanced torque and road fluctuation can seriously influence the control accuracy. In addition, the "blood of hydraulic system," that is, the working oil, will be polluted with the prolonged service life under severe working conditions. Oil contamination will induce oil temperature rise and wear aggravate, which causes leakage increase, pressure instability, and action abnormality, and then result in frequent system failure or end the service life because system performance cannot meet requirements. So, oil contamination will greatly increase the control difficulty, deteriorate the control performance of the tank, and ultimately lead to decreasing equipment reliability and shortening durability, even which can cause casualties and loss of initiative during war. Therefore, the control research of vehicle mounted and unbalanced barrel pitching system under oil contamination condition can greatly improve the reliability of tank and enhance the actual combat capability, which is a major strategic issue related to safety and stability. 


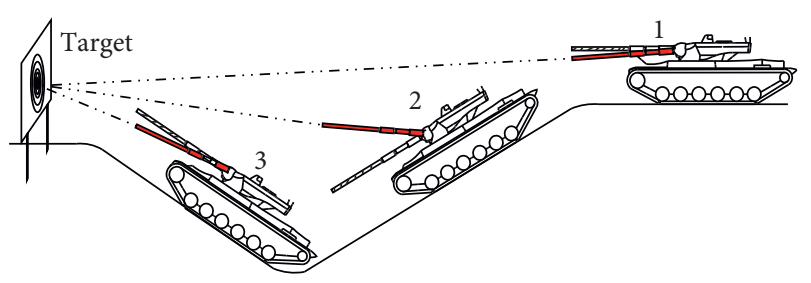

With stabilizer

Without stabilizer

FIgURE 1: Vertical pitching motion of barrel with or without stabilizer.

Around the control of barrel pitching system, scholars have done extensive research, and the result shows that the unbalanced torque is an important reason for the deterioration of control performance. Currently, the method of balancing such imbalances can be attributed to mass balance, balancing machine balance, and adding drive source balance [4]. Among them, the required balance quality for mass balance is large, which is difficult to achieve because of compact and light-weight requirements. Balancing machine balance can achieve light-weight requirements to a certain extent, but it is difficult to achieve compact requirements because of additional mechanical configuration. Therefore, Gao et al. [5] gave a new type of servo system to balance and control the unbalanced barrel, which uses the balance chamber of the three-chamber hydraulic cylinder to compensate the unbalanced force, and the two drive chambers are used for position and interference suppressing, which can achieve precise control of large diameter unbalanced barrel pitching system. Aiming at overcoming road fluctuation's influence, Zhao [6] established a dynamic stability model of the barrel's direct stability system, and analyzed the stability accuracy of the system to compensate the road fluctuation, which has important theoretical value.

In addition, the barrel pitching system is sensitive to oil contamination, and the oil contamination degree has strict requirements. Because of the existence of servo valve, the required oil level of barrel pitching system is no lower than NAS 7. In the service process, the hydraulic system is inevitably mixed with solid particles, gases, and liquids, which will reduce the reliability and increase the control difficulty of barrel pitching system. However, the existing methods pay more attention to active control of oil contamination such as purification and contamination detection, and there is no research on adaptive compensation control for system performance degradation [7].

In conclusion, there is no research on the control of barrel pitching system integratedly considering the effects of road fluctuation, unbalanced torque, and oil contamination. In this work, the overall model of barrel pitching system is established and its sensitivity analysis is conducted, and then the correction link is designed to overcome the influence of road fluctuation, and the pressure difference feedback loop is constructed to overcome the influence of changing unbalanced torque during pitching process. After that the oil contamination influence has been categorized based on the difference of contamination source, and then the core decay parameters induced by oil contamination are determined. At last the PID controller, the fuzzy PID controller, and the fractional order fuzzy PID controller are designed to restrain the complex influence of oil contamination, road fluctuation, and unbalanced torque.

\section{Working Principle and Modeling of the Barrel Pitching System}

2.1. Working Principle. The vehicle mounted and unbalanced barrel pitching system is actually an electro-hydraulic servo control system, the system structure is shown in Figure 2. The speed gyroscope detects pitching speed of barrel in real time and sends it to the controller together with its integral signal. The controller compares it with the given signal and outputs a control voltage signal, and then turns it into a current signal by the servo amplifier to control the proportional valve. The servo valve outputs flow and drives the hydraulic cylinder to move, and it finally drives the barrel to pitch around fulcrum $\mathrm{O}$. In which $T_{L}$ is the unbalanced torque generated by the barrel relative to the fulcrum $\mathrm{O}$. The barrel pitching servo system is mounted on the vehicle, which will sway follow the road fluctuation, and the sensor measures the pressure of hydraulic cylinder's two chambers, which is corrected and sent to servo amplifier for suppressing the influence of unbalanced torque. The gyroscope sensor detects the pitching angle in the vertical direction of the carrier in real time, and then the angle is corrected and sent to servo amplifier for suppressing the influence of road fluctuation.

\subsection{Modeling of the Barrel Pitching System}

2.2.1. Proportional Servo Valve Model. The servo amplifier converts received control voltage $U_{1}(t)$ into output current $I(t)$, and its mathematical model can be approximated to the proportional component shown as follows:

$$
K_{\mathrm{a}}=\frac{I(t)}{U_{1}(t)} \text {. }
$$

The operating frequency of the selected proportional servo valve is much higher than that of the actuator's, so its mathematical model can be expressed as follows:

$$
K_{1}=\frac{Q_{0}(t)}{I(t)}
$$

where $Q_{\mathrm{o}}(t)$ denotes the no-load flow.

Double closed loop feedback of angular position and angular velocity are adopted. The relationship between given voltage $U_{\mathrm{r}}(t)$ of barrel pitching system and received voltage $U_{1}(t)$ of servo amplifier can be expressed as follows:

$$
U_{\mathrm{r}}(t)-k_{\mathrm{l}} \theta-k_{\mathrm{v}} \frac{d \theta}{d t}=U_{1}(t)
$$

where $k_{\mathrm{l}}$ and $k_{\mathrm{v}}$ denotes the feedback coefficient of angular position and angular velocity and $\theta$ denotes the input angle of position sensor and velocity sensor. 


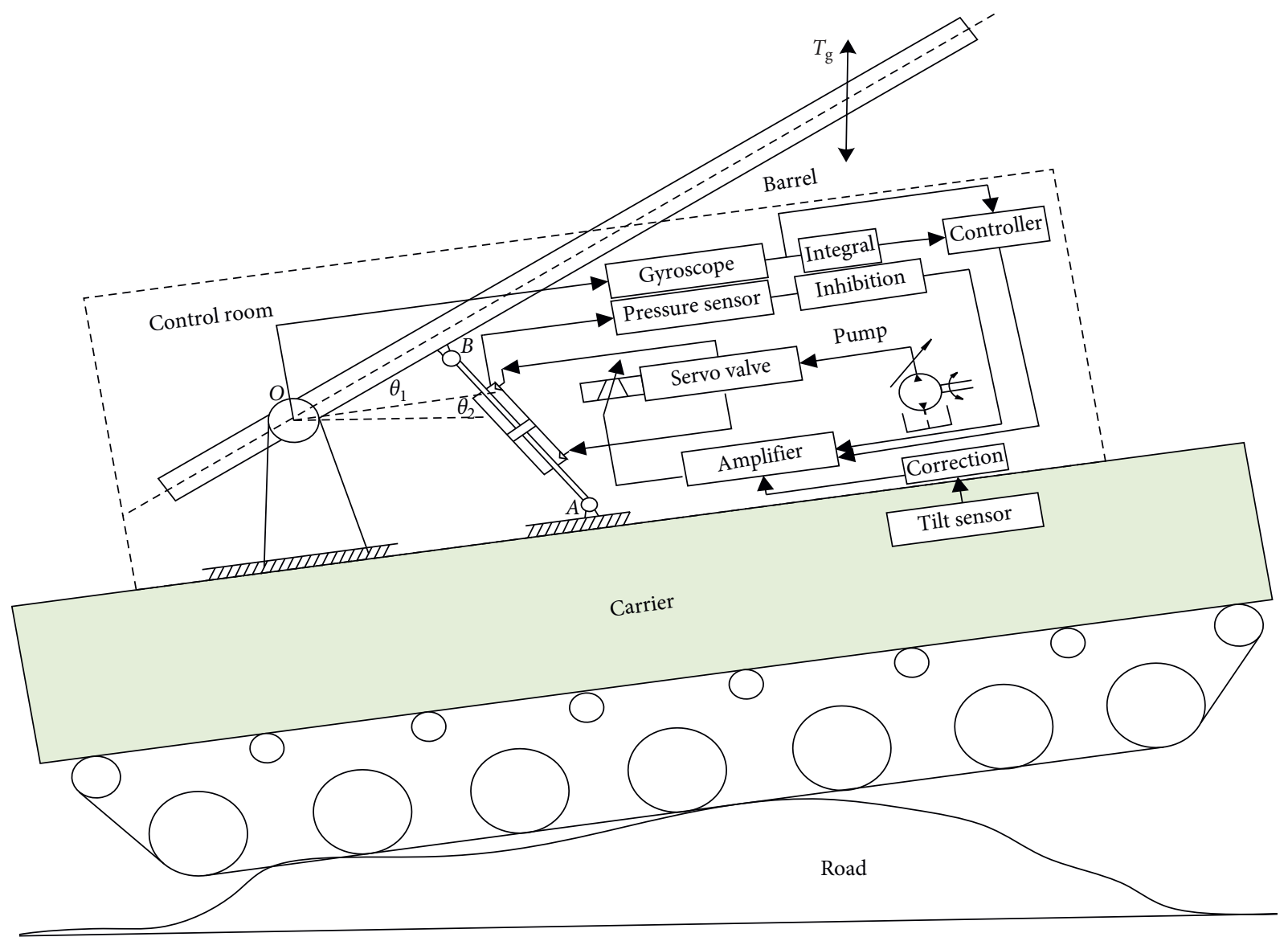

FIGURE 2: Vehicle mounted and unbalanced barrel pitching system structure.

2.2.2. Variable Pump and Hydraulic Cylinder Model. Ignoring the smaller return oil pressure, the continuous flow equation for variable pump and hydraulic cylinder is as follows:

$$
U_{1}(t) K_{\mathrm{a}} K_{1}-C_{\mathrm{t}} p_{1}(t)=A \frac{d l}{d t}+\frac{V_{0}}{\beta_{\mathrm{e}}} \frac{d p_{1}(t)}{d t},
$$

where $p_{1}$ denotes the inlet pressure, $C_{\mathrm{t}}$ denotes the leakage coefficient, $A$ denotes the effective area of piston, $L$ denotes the displacement of piston rod, $V_{0}$ denotes the single chamber volume of cylinder, and $\beta_{\mathrm{e}}$ denotes the volume elastic modulus of oil.

In Figure 2, set $\theta_{1}$ as the pitching angle of barrel relative to the vehicle and $\theta_{2}$ as the rotation angle of vehicle relative to the inertial space around the rotation axis. The rotation angle of barrel relative to the inertial space around rotation axis is as follows:

$$
\theta=\theta_{1}+\theta_{2} .
$$

Since the pitching angle $\theta_{1}$ of barrel is the control variable, it is necessary to establish the relationship between the output displacement of piston rod $l$ and the pitching angle $\theta_{1}$. Set the length of $A B$ in Figure 2 as follows:

$$
l+l_{3}=\sqrt{l_{1}^{2}+l_{2}^{2}-2 l_{1} l_{2} \cos \left(\gamma+\theta_{1}\right)}
$$

where $l_{1}$ denotes the length of $\mathrm{OA}, l_{2}$ denotes the length of $\mathrm{OB}, l_{3}$ denotes the length of $\mathrm{AB}$ when the rotation angle of barrel is 0 degree, and $\gamma+\theta_{1}$ is the angle between OA and $\mathrm{OB}$. Take the derivative of equation (6) about $t$, it can be obtained as

$$
\frac{d l}{d t}=\frac{l_{1} l_{2} \sin \left(\gamma+\theta_{1}\right)}{\sqrt{l_{1}^{2}+l_{2}^{2}-2 l_{1} l_{2} \cos \left(\gamma+\theta_{1}\right)}} \frac{d \theta_{1}}{d t}=L \frac{d \theta_{1}}{d t} .
$$

Based on equations (3)-(5) and (7), the continuous flow equation of hydraulic pump and cylinder can be obtained as follows:

$$
\begin{gathered}
\left(U_{\mathrm{r}}(t)-k_{\mathrm{l}} \theta_{1}-k_{\mathrm{l}} \theta_{2}-k_{\mathrm{v}} \frac{d \theta_{1}}{d t}-k_{\mathrm{v}} \frac{d \theta_{2}}{d t}\right) K_{\mathrm{a}} K_{1} \\
-\left(C_{t} p_{1}(t)+\frac{V_{0}}{\beta_{\mathrm{e}}} \frac{d p_{1}(t)}{d t}\right)=A L \frac{d \theta_{1}}{d t} .
\end{gathered}
$$

The balance equation between cylinder and load is as follows:

$$
M=J \frac{d^{2} \theta_{1}}{d t^{2}}+J \frac{d^{2} \theta_{2}}{d t^{2}}+B_{\mathrm{m}} \frac{d \theta_{1}}{d t}+T_{\mathrm{g}}
$$

where $M$ denotes the output torque of the hydraulic cylinder, $J$ denotes the rotational inertia of barrel relative to the 
trunnion, $B_{\mathrm{m}}$ denotes the viscous friction coefficient, and $T_{\mathrm{g}}$ denotes the unbalanced torque.

The output torque $M$ of the hydraulic cylinder is the product of output force versus arm of output force relative to barrel rotation center:

$$
M=p_{1} \cdot A \cdot L
$$

2.2.3. State Space Model. Based on equations (8)-(10) and assuming $x_{1}=\theta_{1}, x_{2}=\dot{\theta}_{1}$, and $x_{3}=\ddot{\theta}_{1}$, the state space model of barrel pitching system can be obtained as equation (11), from which the factors affecting control performance include external disturbance and internal parameter disturbance. The former includes unbalanced torque $T_{\mathrm{g}}$ and road fluctuation $\theta_{2}$, and the latter includes parameter change induced by working conditions such as oil pollution. Therefore, firstly the sensitivity analysis of each parameter to system performance should be analyzed to find out the more sensitive factors. Secondly, the isolation design of external disturbances should be carried out. Finally, an effective controller should be designed to effectively suppress the sensitive factors and external disturbances.

$$
\left\{\begin{array}{l}
y=x_{1}+\theta_{2}, \\
\dot{x}_{1}=x_{2}, \\
\dot{x}_{2}=x_{3} \\
\dot{x}_{3}=-k_{1} x_{1}-k_{2} x_{2}-k_{3} x_{3}+b u-d_{1} f_{\mathrm{u}}-d_{2} f_{\mathrm{r}},
\end{array}\right.
$$

where $k_{1}=\left(\beta_{\mathrm{e}} k_{\mathrm{l}} K_{\mathrm{a}} K_{1} A L / J V_{0}\right)$,

$$
\begin{aligned}
k_{2} & =\frac{\beta_{\mathrm{e}}\left(A L k_{\mathrm{v}} K_{\mathrm{a}} K_{1}+C_{\mathrm{t}} B_{\mathrm{m}}+(A L)^{2}\right)}{J V_{0}}, \\
k_{3} & =\frac{\beta_{\mathrm{e}}\left(J C_{\mathrm{t}}+\left(V_{0} B_{\mathrm{m}} / \beta_{\mathrm{e}}\right)\right)}{J V_{0}}, \\
b & =\frac{\beta_{\mathrm{e}} K_{\mathrm{a}} K_{1} A L}{J V_{0}}, \\
d_{1} & =\frac{\beta_{\mathrm{e}} C_{\mathrm{t}}}{J V_{0}}, \\
f_{\mathrm{u}} & =\left(\frac{V_{0}}{\beta_{\mathrm{e}} C_{\mathrm{t}}} \dot{T}_{\mathrm{g}}+T_{\mathrm{g}}\right), \\
d_{2} & =\frac{A L \beta_{\mathrm{e}}}{J V_{0}}, \\
f_{\mathrm{r}} & =\left(\frac{J V_{0}}{A L \beta_{e}} \ddot{\theta}_{2}+\frac{C_{\mathrm{t}} B_{\mathrm{m}}}{A L} \ddot{\theta}_{2}+k_{\mathrm{v}} K_{\mathrm{a}} K_{1} \dot{\theta}_{2}+k_{\mathrm{l}} K_{\mathrm{a}} K_{1} \theta_{2}\right) .
\end{aligned}
$$

\section{Sensitivity Analysis of the Barrel Pitching System}

The sensitivity analysis of the barrel pitching system is carried out using the first order trajectory sensitivity model [8]. Trajectory sensitivity is to study the change of state vector caused by the change of parameters according to the state equation. The state equation of the barrel pitching system can be expressed as follows:

$$
\dot{\mathbf{x}}=\mathbf{f}(\mathbf{x}, \mathbf{u}, \boldsymbol{\alpha}, t),
$$

where $\mathbf{x}$ is $N$ dimensional state vector, $\mathbf{u}$ is $R$ dimensional input independent of $\boldsymbol{\alpha}$, and $t$ is time.

The solution of equation (13) is expressed as follows:

$$
x_{n}(t)=\varphi\left(t, \boldsymbol{\alpha}_{n}\right) \text {. }
$$

The sensitivity function of vector $\mathbf{x}$ to parameter $\boldsymbol{\alpha}$ and its initial condition are defined as

$$
\begin{aligned}
& \lambda^{i}=\frac{\partial \mathbf{x}}{\partial \alpha_{i}}, \quad i=1,2, \ldots, p, \\
& \lambda_{0}^{i}=\frac{\partial \mathbf{x}_{0}}{\partial \alpha_{i}}, \quad i=1,2, \ldots, p .
\end{aligned}
$$

In this work, $\mathbf{u}$ and $\boldsymbol{\alpha}$ are independent, taking the derivative of equation (13) on both sides of $\boldsymbol{\alpha}$ as

$$
\dot{\lambda}^{i}=\left(\frac{\partial \mathbf{f}}{\partial x}\right)_{n} \lambda^{i}+\left(\frac{\partial \mathbf{f}}{\partial \alpha_{i}}\right)_{n}, \quad i=1,2, \ldots, p .
$$

Select related vector of barrel pitching system as

$$
\left\{\begin{array}{l}
\mathbf{x}=\left(x_{1}, x_{2}, x_{3}\right), \\
\mathbf{u}=\left(u_{1}, u_{2}, u_{3}\right), \\
\boldsymbol{\alpha}=\left(\alpha_{1}, \alpha_{2}, \ldots, \alpha_{11}\right),
\end{array}\right.
$$

where the state vector parameters of barrel system are $x_{1}=\theta_{1}, x_{2}=\dot{\theta}_{1}$, and $x_{3}=\ddot{\theta}_{1}$; the input vector parameters are $u_{1}=U_{\mathrm{r}}, u_{2}=T_{\mathrm{g}}$, and $u_{3}=\theta_{2}$; and the independent vector parameters are $\alpha_{1}=K_{\mathrm{a}}, \alpha_{2}=K_{1}, \alpha_{3}=A, \alpha_{4}=L, \alpha_{5}=C_{\mathrm{t}}$, $\alpha_{6}=V_{0}, \alpha_{7}=\beta_{\mathrm{e}}, \alpha_{8}=B_{\mathrm{m}}, \alpha_{9}=J, \alpha_{10}=k_{1}$, and $\alpha_{11}=k_{\mathrm{v}}$.

Then the state space model of barrel pitching system can be expanded into the following equation:

$$
\left\{\begin{array}{l}
y=x_{1}+\theta_{2}, \\
\dot{x}_{1}=x_{2}, \\
\dot{x}_{2}=x_{3}, \\
\dot{x}_{3}=-\frac{\alpha_{7} \alpha_{10} \alpha_{1} \alpha_{2} \alpha_{3} \alpha_{4}}{\alpha_{9} \alpha_{6}} x_{1}-\frac{\alpha_{7}\left(\alpha_{3} \alpha_{4} \alpha_{11} \alpha_{1} \alpha_{2}+\alpha_{5} \alpha_{8}+\alpha_{3}^{2} \alpha_{4}^{2}\right)}{\alpha_{9} \alpha_{6}} x_{2} \\
-\frac{\alpha_{7} \alpha_{9} \alpha_{5}+\alpha_{6} \alpha_{8}}{\alpha_{9} \alpha_{6}} x_{3}+\frac{\alpha_{7} \alpha_{1} \alpha_{2} \alpha_{3} \alpha_{4}}{\alpha_{9} \alpha_{6}} u_{1}-\frac{\alpha_{7} \alpha_{5}}{\alpha_{9} \alpha_{6}}\left(\frac{\alpha_{6}}{\alpha_{7} \alpha_{5}} \dot{u}_{2}+u_{2}\right) \\
-\frac{\alpha_{7}}{\alpha_{9} \alpha_{6}}\left(\left(\frac{\alpha_{6} \alpha_{8}}{\alpha_{7}}+\alpha_{9} \alpha_{5}-\alpha_{8} \alpha_{5}\right) \ddot{u}_{3}+\left(\alpha_{8} \alpha_{5}+\alpha_{3}^{2} \alpha_{4}^{2}\right) \dot{u}_{3}\right) .
\end{array}\right.
$$

The partial derivative of state equation function to the state vector $\mathbf{x}$ is conducted, and then the coefficient term of sensitivity function can be obtained as equation (19). 
The partial derivative of state equation function to the state vector $\boldsymbol{\alpha}$ is conducted, and then the free term of sensitivity function can be obtained as equation (20).

$$
\begin{aligned}
& \left\{\begin{array}{l}
\frac{\partial \mathbf{f}}{\partial x_{1}}=\left(0,0,-\frac{\alpha_{7} \alpha_{10} \alpha_{1} \alpha_{2} \alpha_{3} \alpha_{4}}{\alpha_{9} \alpha_{6}}\right)^{T}, \\
\frac{\partial \mathbf{f}}{\partial x_{2}}=\left(1,0,-\frac{\alpha_{7}\left(\alpha_{3} \alpha_{4} \alpha_{11} \alpha_{1} \alpha_{2}+\alpha_{5} \alpha_{8}+\alpha_{3}^{2} \alpha_{4}^{2}\right)}{\alpha_{9} \alpha_{6}}\right)^{T}, \\
\frac{\partial \mathbf{f}}{\partial x_{3}}=\left(0,1,-\frac{\alpha_{7} \alpha_{9} \alpha_{5}+\alpha_{6} \alpha_{8}}{\alpha_{9} \alpha_{6}}\right)^{T}
\end{array}\right. \\
& \frac{\partial \mathbf{f}}{\partial \alpha_{1}}=\left(0,0,-\frac{\alpha_{7} \alpha_{10} \alpha_{2} \alpha_{3} \alpha_{4}}{\alpha_{9} \alpha_{6}} x_{1}-\frac{\alpha_{7} \alpha_{3} \alpha_{4} \alpha_{11} \alpha_{2}}{\alpha_{9} \alpha_{6}} x_{2}+\frac{\alpha_{7} \alpha_{2} \alpha_{3} \alpha_{4}}{\alpha_{9} \alpha_{6}} u_{1}\right)^{T} \\
& \frac{\partial \mathbf{f}}{\partial \alpha_{2}}=\left(0,0,-\frac{\alpha_{7} \alpha_{10} \alpha_{1} \alpha_{3} \alpha_{4}}{\alpha_{9} \alpha_{6}} x_{1}-\frac{\alpha_{7} \alpha_{3} \alpha_{4} \alpha_{11} \alpha_{1}}{\alpha_{9} \alpha_{6}} x_{2}+\frac{\alpha_{7} \alpha_{1} \alpha_{3} \alpha_{4}}{\alpha_{9} \alpha_{6}} u_{1}\right)^{T} \text {, } \\
& \frac{\partial \mathbf{f}}{\partial \alpha_{3}}=\left(0,0,-\frac{\alpha_{7} \alpha_{10} \alpha_{1} \alpha_{2} \alpha_{4}}{\alpha_{9} \alpha_{6}} x_{1}-\frac{\alpha_{7}\left(\alpha_{4} \alpha_{11} \alpha_{1} \alpha_{2}+2 \alpha_{3} \alpha_{4}^{2}\right)}{\alpha_{9} \alpha_{6}} x_{2}+\frac{\alpha_{7} \alpha_{1} \alpha_{2} \alpha_{4}}{\alpha_{9} \alpha_{6}} u_{1}-\frac{2 \alpha_{7} \alpha_{3} \alpha_{4}^{2}}{\alpha_{9} \alpha_{6}} \dot{u}_{3}\right)^{T}, \\
& \frac{\partial \mathbf{f}}{\partial \alpha_{4}}=\left(0,0,-\frac{\alpha_{7} \alpha_{10} \alpha_{1} \alpha_{2} \alpha_{3}}{\alpha_{9} \alpha_{6}} x_{1}-\frac{\alpha_{7}\left(\alpha_{3} \alpha_{11} \alpha_{1} \alpha_{2}+2 \alpha_{3}^{2} \alpha_{4}\right)}{\alpha_{9} \alpha_{6}} x_{2}+\frac{\alpha_{7} \alpha_{1} \alpha_{2} \alpha_{3}}{\alpha_{9} \alpha_{6}} u_{1}-\frac{2 \alpha_{7} \alpha_{4} \alpha_{3}^{2}}{\alpha_{9} \alpha_{6}} \dot{u}_{3}\right)^{T} \text {, } \\
& \frac{\partial \mathbf{f}}{\partial \alpha_{5}}=\left(0,0,-\frac{\alpha_{7} \alpha_{8}}{\alpha_{9} \alpha_{6}} x_{2}-\frac{\alpha_{7}}{\alpha_{6}} x_{3}-\frac{\alpha_{7}}{\alpha_{9} \alpha_{6}} u_{2}-\frac{\alpha_{7}}{\alpha_{9} \alpha_{6}}\left(\left(\alpha_{9}-\alpha_{8}\right) \ddot{u}_{3}+\alpha_{8} \dot{u}_{3}\right)\right)^{T} \text {, } \\
& \frac{\partial \mathbf{f}}{\partial \alpha_{6}}=\left(0,0, \frac{\alpha_{7} \alpha_{10} \alpha_{1} \alpha_{2} \alpha_{3} \alpha_{4}}{\alpha_{9} \alpha_{6}^{2}} x_{1}+\frac{\alpha_{7}\left(\alpha_{3} \alpha_{4} \alpha_{11} \alpha_{1} \alpha_{2}+\alpha_{5} \alpha_{8}+\alpha_{3}^{2} \alpha_{4}^{2}\right)}{\alpha_{9} \alpha_{6}^{2}} x_{2}+\frac{\alpha_{7} \alpha_{5}}{\alpha_{6}^{2}} x_{3}-\frac{\alpha_{7} \alpha_{1} \alpha_{2} \alpha_{3} \alpha_{4}}{\alpha_{9} \alpha_{6}^{2}} u_{1}+\frac{\alpha_{7} \alpha_{5}}{\alpha_{9} \alpha_{6}^{2}} u_{2}\right. \\
& \left.+\frac{\alpha_{7}}{\alpha_{9} \alpha_{6}^{2}}\left(\left(\alpha_{9} \alpha_{5}-\alpha_{8} \alpha_{5}\right) \ddot{u}_{3}+\left(\alpha_{8} \alpha_{5}+\alpha_{3}^{2} \alpha_{4}^{2}\right) \dot{u}_{3}\right)\right)^{T} \text {, } \\
& \frac{\partial \mathbf{f}}{\partial \alpha_{7}}=\left(0,0,-\frac{\alpha_{10} \alpha_{1} \alpha_{2} \alpha_{3} \alpha_{4}}{\alpha_{9} \alpha_{6}} x_{1}-\frac{\alpha_{3} \alpha_{4} \alpha_{11} \alpha_{1} \alpha_{2}+\alpha_{5} \alpha_{8}+\alpha_{3}^{2} \alpha_{4}^{2}}{\alpha_{9} \alpha_{6}} x_{2}-\frac{\alpha_{5}}{\alpha_{6}} x_{3}+\frac{\alpha_{1} \alpha_{2} \alpha_{3} \alpha_{4}}{\alpha_{9} \alpha_{6}} u_{1}-\frac{\alpha_{5}}{\alpha_{9} \alpha_{6}} u_{2}\right. \\
& \left.-\frac{1}{\alpha_{9} \alpha_{6}}\left(\left(\alpha_{9} \alpha_{5}-\alpha_{8} \alpha_{5}\right) \ddot{u}_{3}+\left(\alpha_{8} \alpha_{5}+\alpha_{3}^{2} \alpha_{4}^{2}\right) \dot{u}_{3}\right)\right)^{T} \text {, } \\
& \frac{\partial \mathbf{f}}{\partial \alpha_{8}}=\left(0,0,-\frac{\alpha_{7} \alpha_{5}}{\alpha_{9} \alpha_{6}} x_{2}-\frac{1}{\alpha_{9}} x_{3}-\frac{\alpha_{7}}{\alpha_{9} \alpha_{6}}\left(\left(\frac{\alpha_{6}}{\alpha_{7}}-\alpha_{5}\right) \ddot{u}_{3}+\alpha_{5} \dot{u}_{3}\right)\right)^{T} \text {, } \\
& \frac{\partial \mathbf{f}}{\partial \alpha_{9}}=\left(0,0, \frac{\alpha_{7} \alpha_{10} \alpha_{1} \alpha_{2} \alpha_{3} \alpha_{4}}{\alpha_{9}^{2} \alpha_{6}} x_{1}+\frac{\alpha_{7}\left(\alpha_{3} \alpha_{4} \alpha_{11} \alpha_{1} \alpha_{2}+\alpha_{5} \alpha_{8}+\alpha_{3}^{2} \alpha_{4}^{2}\right)}{\alpha_{9}^{2} \alpha_{6}} x_{2}+\frac{\alpha_{8}}{\alpha_{9}^{2}} x_{3}-\frac{\alpha_{7} \alpha_{1} \alpha_{2} \alpha_{3} \alpha_{4}}{\alpha_{9}^{2} \alpha_{6}} u_{1}\right. \\
& \left.+\frac{\alpha_{7} \alpha_{5}}{\alpha_{9}^{2} \alpha_{6}}\left(\frac{\alpha_{6}}{\alpha_{7} \alpha_{5}} \dot{u}_{2}+u_{2}\right)+\frac{\alpha_{7}}{\alpha_{9}^{2} \alpha_{6}}\left(\left(\frac{\alpha_{6} \alpha_{8}}{\alpha_{7}}-\alpha_{8} \alpha_{5}\right) \ddot{u}_{3}+\left(\alpha_{8} \alpha_{5}+\alpha_{3}^{2} \alpha_{4}^{2}\right) \dot{u}_{3}\right)\right)^{T}, \\
& \frac{\partial \mathbf{f}}{\partial \alpha_{10}}=\left(0,0,-\frac{\alpha_{7} \alpha_{1} \alpha_{2} \alpha_{3} \alpha_{4}}{\alpha_{9} \alpha_{6}} x_{1}\right)^{T} \text {, } \\
& \frac{\partial \mathbf{f}}{\partial \alpha_{11}}=\left(0,0,-\frac{\alpha_{7} \alpha_{3} \alpha_{4} \alpha_{1} \alpha_{2}}{\alpha_{9} \alpha_{6}} x_{2}\right)^{T} \text {. }
\end{aligned}
$$


The initial value of state vector $\mathbf{x}$ is $\mathbf{x}_{0}=0$, and then the initial value of sensitivity function is as follows:

$$
\lambda_{0}^{i}=0, \quad i=1,2, \ldots, 11 .
$$

The trajectory sensitivity equation (16) is a first order linear non-homogeneous differential equation with time varying coefficients. There are $n \times(p+1)$ equations to be solved, including $n$ state equations and $n \times p$ sensitivity equations. In this work, only the sensitivity of barrel's pitching angle $x_{1}$ to the parameter vector $\boldsymbol{\alpha}$ is considered.

The simulation model of barrel pitching system is established in MATLAB/Simulink. The initial value of parameters is shown in Table 1.

Figure 3 is the step response of barrel pitching system, the setting time is more than $2 \mathrm{~s}$, the steady state curve is sine curve and its magnitude is almost $0.007 \mathrm{rad}$, and the steady state error is $0.001 \mathrm{rad}$, which cannot satisfy the requirements.

Based on the simulation model, the differential equation is solved in the command interface of MATLAB using the fourth-order/fifth-order Runge-Kutta algorithm, and then the sensitivity function $\lambda_{1}^{i}(i=1,2, \ldots, 11)$ of step response $x_{1}$ to the parameter $\boldsymbol{\alpha}_{i}(i=1,2, \ldots, 11)$ is shown in Figure 4.

Comparing Figures 3 and 4 , it can be seen that the parameters $\alpha_{1}, \alpha_{2}, \alpha_{3}, \alpha_{4}, \alpha_{6}, \alpha_{7}, \alpha_{8}, \alpha_{9}$, and $\alpha_{11}$ only have a greater influence during the setting time; the parameters $\alpha_{5}$ and $\alpha_{10}$ have an effect on the output angle during all sampling time. And the sinusoidal curves with large magnitude are induced by the road fluctuation, which needs further suppression. In order to quantify the influence of each parameter, the percentage of output angle's change $\Delta x_{1}$ relative to the angle's step value $s x_{1}$ is shown in Figure 5, and the maximum influence value of each parameter on the output angle is shown in Figure 6. It is clear that the values of $\alpha_{5}$ and $\alpha_{10}$ are small, although the values of $\alpha_{1}, \alpha_{3}, \alpha_{4}, \alpha_{6}, \alpha_{9}$, and $\alpha_{11}$ are no less than 5\%. Actually, the change of parameter's value can be neglected after the barrel pitching system is determined, so it is necessary to carry out impact analysis and control of $\alpha_{2}, \alpha_{7}$, and $\alpha_{8}$, which have great influence and will change with oil pollution.

\section{External Interference and Its Correction}

4.1. Road Fluctuation and Its Isolation Model. Based on the model of barrel pitching system, the control diagram can be obtained as shown in Figure 7. $G_{1}(s)$ is the corrective component, and its function is to compensate the influence of $\theta_{2} J s^{2}$. The control command $U_{\mathrm{r}}$ and unbalanced torque $T_{\mathrm{g}}$ are both set as 0 , and the transfer function of output angle $\theta$ with respect to the road fluctuation signal $\theta_{2}$ is obtained as

$$
\begin{aligned}
\varphi(s)= & \frac{G_{1}(s) F_{2}(s) F_{3}(s)}{1+\left[K_{1} F_{1}(s)+K_{\mathrm{v}} s\right] F_{2}(s) F_{3}(s)} \\
& -\frac{J s^{2}\left(\left(V_{0} / B_{\mathrm{e}}\right) s+C_{t}\right)\left(F_{3}(s) / A L\right)-1}{1+\left[K_{1} F_{1}(s)+K_{\mathrm{v}} s\right] F_{2}(s) F_{3}(s)},
\end{aligned}
$$

where $F_{1}(s), F_{2}(s)$, and $F_{3}(s)$ are denoted as follows:
TABLE 1: Values of parameter and input vector.

\begin{tabular}{lc}
\hline Parameter & Value \\
\hline$k_{\mathrm{a}}$ & $0.0012 \mathrm{~A} / \mathrm{V}$ \\
$k_{1}$ & $0.056 \mathrm{~m}^{3} /(\mathrm{s} \cdot \mathrm{A})$ \\
$A$ & $9 e-3 \mathrm{~m}^{2}$ \\
$L$ & $0.314 \mathrm{~m}$ \\
$C_{\mathrm{t}}$ & $1.5 e-13\left(\mathrm{~m}^{3} / \mathrm{s}\right) / \mathrm{Pa}$ \\
$V_{0}$ & $9.735 e-5 \mathrm{~m}^{3}$ \\
$\beta_{\mathrm{e}}$ & $700 \mathrm{MPa}$ \\
$B_{\mathrm{m}}$ & $238 \mathrm{Nm} /(\mathrm{rad} / \mathrm{s})$ \\
$J$ & $3400 \mathrm{~kg} \cdot \mathrm{m}^{2}$ \\
$k_{1}$ & $1 \mathrm{~V} / \mathrm{rad}$ \\
$k_{\mathrm{v}}$ & $57 \mathrm{~V} /(\mathrm{rad} / \mathrm{s})$ \\
$\theta_{2}$ & $1^{\circ}, 1 \mathrm{~Hz}$ \\
$T_{\mathrm{g} 0}$ & $1000 \mathrm{Nm}$ \\
\hline
\end{tabular}

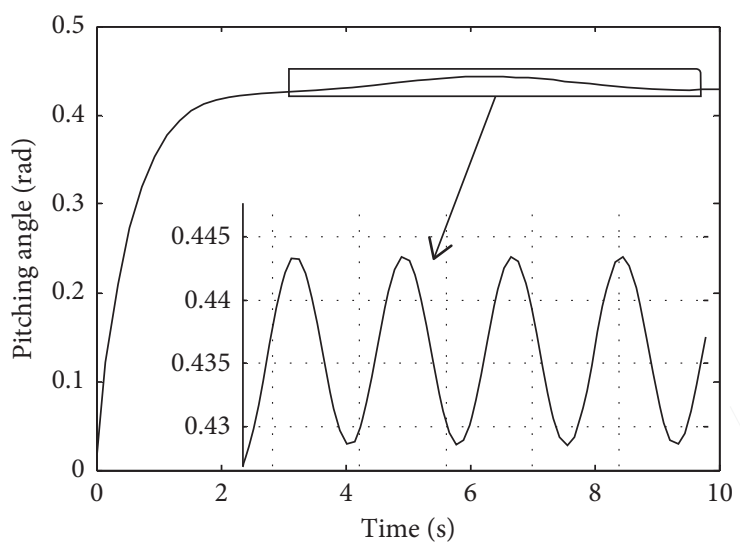

FIgURE 3: Step response of barrel pitching system.

$$
\begin{aligned}
& F_{1}(s)=K_{p}+\frac{K_{i}}{s}+K_{d} s, \\
& F_{2}(s)=K_{\mathrm{a}} K_{1}, \\
& F_{3}(s)=\frac{1 / A L}{s+(1 / A L)\left(\left(V_{0} / B_{\mathrm{e}}\right) s+C_{t}\right)\left(J s^{2}+B_{\mathrm{m}} s\right)} .
\end{aligned}
$$

To compensate for the effect of $\theta_{2} J s^{2}$, we can get the following equation:

$$
\begin{aligned}
G_{1}(s)= & \frac{J s^{2}\left(\left(V_{0} / B_{\mathrm{e}}\right) s+C_{\mathrm{t}}\right)(1 / A L)-A L s}{K_{\mathrm{a}} K_{1}} \\
& -\frac{\left(J s^{2}+B_{\mathrm{m}} s\right)\left(\left(V_{0} / B_{\mathrm{e}}\right) s+C_{\mathrm{t}}\right)}{K_{\mathrm{a}} K_{1}} .
\end{aligned}
$$

4.2. Unbalanced Torque and Its Suppression Model. If $T_{\mathrm{g} 0}$ is the unbalanced torque at 0 degree, the unbalanced torque $T_{\mathrm{g}}$ varies with the pitching angle:

$$
T_{\mathrm{g}}=T_{\mathrm{g} 0} \cdot \cos (\theta) \text {. }
$$

In Figure $7, G_{2}(s)$ is the pressure feedback loop that suppresses the influence of unbalanced torque. The control 


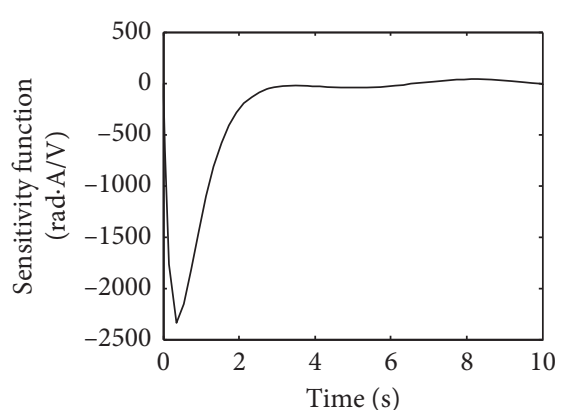

(a)

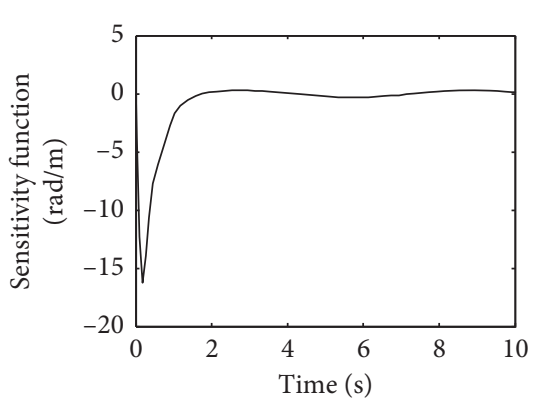

(d)

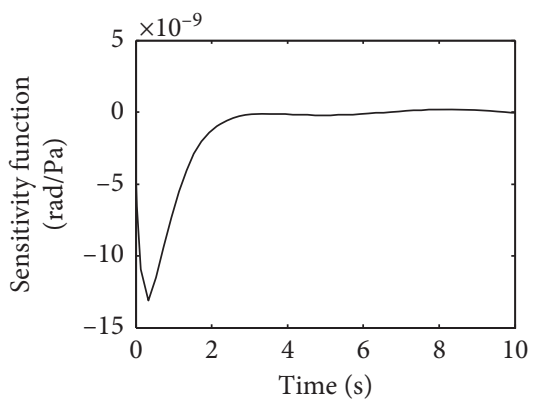

(g)

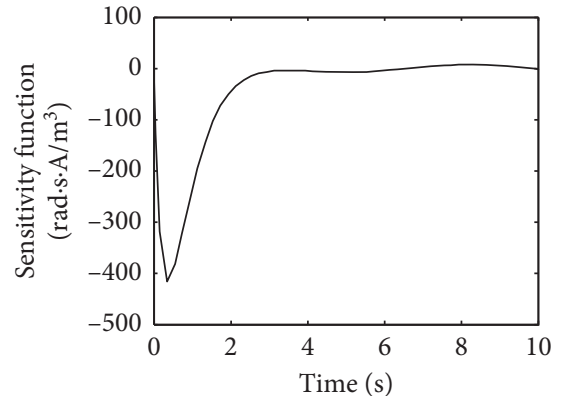

(b)

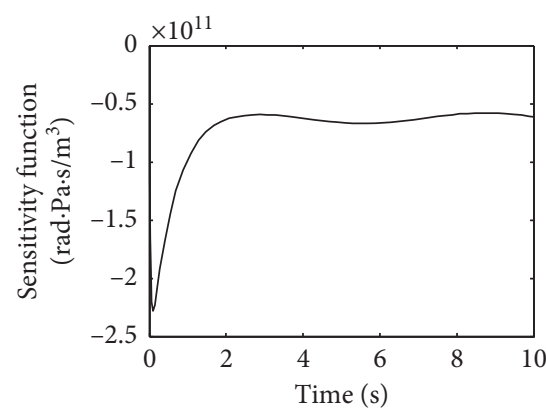

(e)

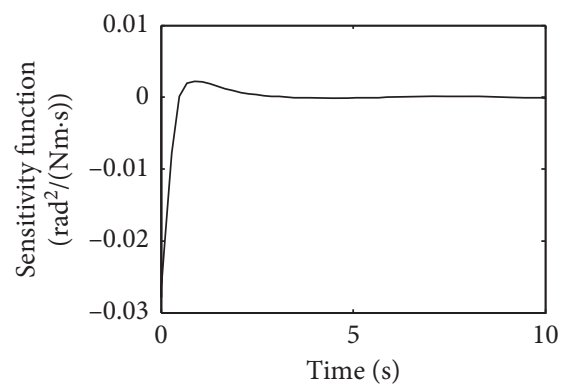

(h)

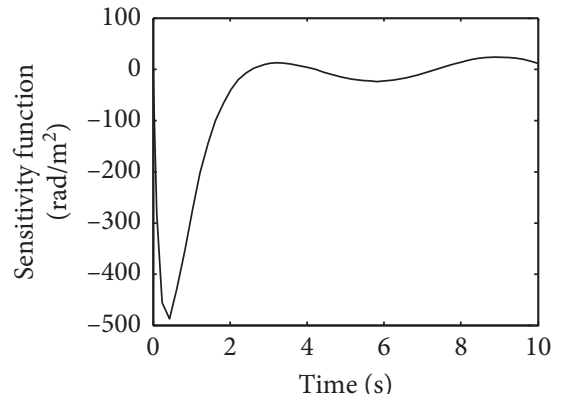

(c)

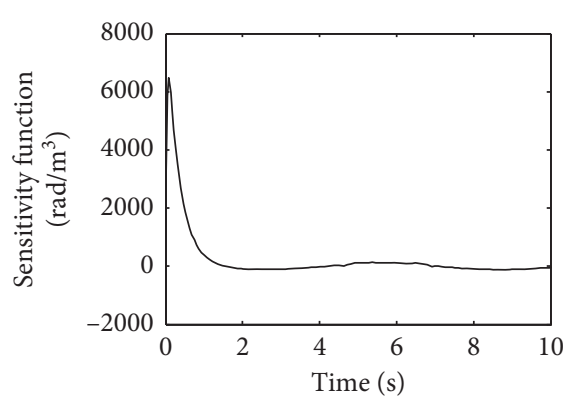

(f)

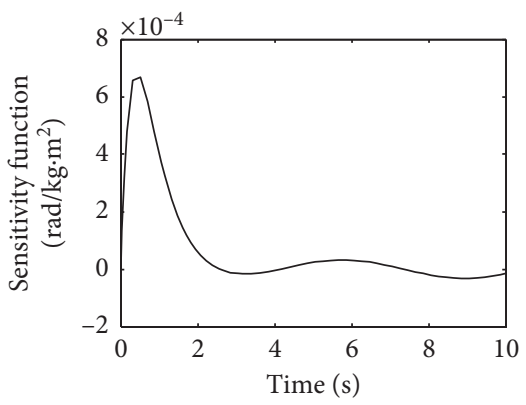

(i)

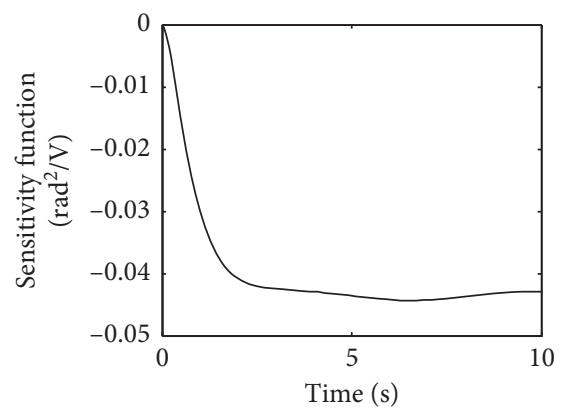

(j)

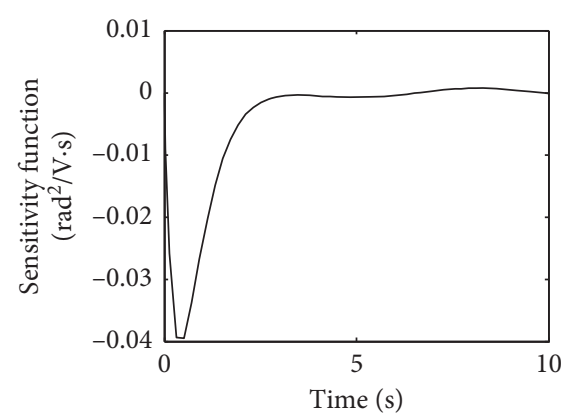

(k)

FIGURE 4: Curves of sensitivity function. (a) Sensitivity function $\lambda_{1}^{1}$. (b) Sensitivity function $\lambda_{1}^{2}$. (c) Sensitivity function $\lambda_{1}^{3}$. (d) Sensitivity function $\lambda_{1}^{4}$. (e) Sensitivity function $\lambda_{1}^{5}$. (f) Sensitivity function $\lambda_{1}^{6}$. (g) Sensitivity function $\lambda_{1}^{7}$. (h) Sensitivity function $\lambda_{1}^{8}$. (i) Sensitivity function $\lambda_{1}^{9}$. (j) Sensitivity function $\lambda_{1}^{10}$. (k) Sensitivity function $\lambda_{1}^{11}$.

command $U_{\mathrm{r}}$ and road fluctuation $\theta_{2}$ are both set as 0 , the transfer function of the output angle $\theta$ with respect to unbalanced torque $T_{\mathrm{g}}$ is obtained as equation (26).
Combining equation (26) and the parameters' value, it is found that the influence of unbalanced torque's change on steady state accuracy is mainly derived from equation (27). 


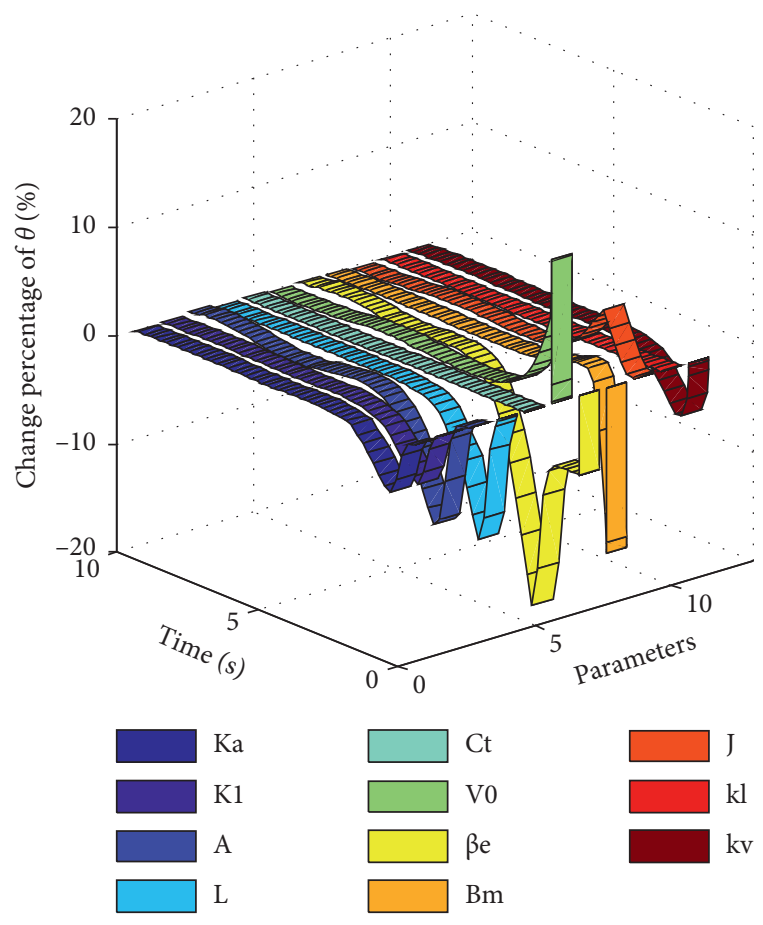

FIGURE 5: $x_{1}$ 's change percentage induced by $\Delta \alpha$.

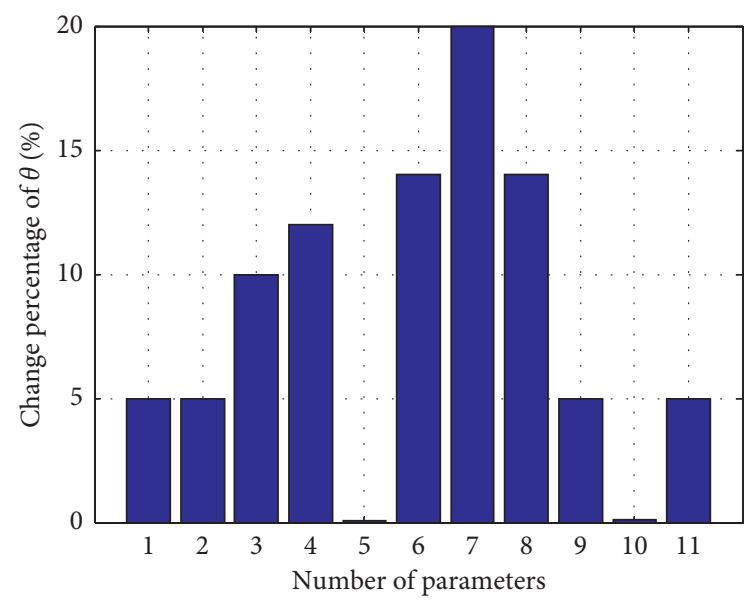

FIgURE 6: Maximum influence value of $\Delta \alpha$ to $x_{1}$.

$$
\begin{aligned}
\psi(s)= & \left(G_{2}(s) F_{2}(s)+\frac{V_{0}}{B_{\mathrm{e}}} s+C_{t}\right) \\
& \cdot \frac{K^{2}}{\left(\left(V_{0} / B_{\mathrm{e}}\right) s+C_{\mathrm{t}}\right)\left(J s^{2}+B_{\mathrm{m}} s\right) K^{2}+K K_{\mathrm{v}} s^{2} F_{2}(s)+s+K K_{\mathrm{l}} s F_{1}(s)},
\end{aligned}
$$

$$
T_{\mathrm{e}}=G_{2}(s) F_{2}(s)+C_{\mathrm{t}} .
$$

So the transfer function of pressure feedback loop can be obtained as follows:

$$
G_{2}(s)=-\frac{C_{t}}{\left(K_{a} K_{1}\right)} .
$$

\section{Influence of Oil Contamination on Barrel Pitching System}

The failures of hydraulic system caused by oil contamination can directly affect its reliability and durability, where oil contaminant refers to substances that are mixed into the oil and have a harmful effect on the performance and service life of control system, which mainly includes solid particles, gases, and liquids.

The failures caused by oil contamination can be divided into two classes: sudden failures and gradual failures. The latter is defined as a condition when a performance indicator cannot be maintained within a specified range [9]. Under coupled action of pollutants, the technical state such as viscosity and elastic modulus will change, also the structural parameters such as the throttling edge of spool valve will be degraded. Before final failure, the control method proposed can delay the gradual degradation process.

5.1. Solid Particles. Solid particle contamination is the most common and hazardous pollutant in hydraulic system. The oil flow with solid particle at a certain speed and angle will cause wear on the internal surface of material. The wear is mainly distributed in spool valve of the barrel pitching system, and the throttle model of spool valve is shown in Figure 8.

The radial clearance $\Delta$ and the throttle edge radius $r_{1}$ and $r_{2}$ will increase because of wear, so the equivalent opening amount of the same spool displacement $x_{\mathrm{v}}$ becomes as large as equation (29), which brings about the flow coefficient increasing sharply and stabilizing at a certain value as the spool displacement continues to increase. So, the flow coefficient $K_{1}$ will increase:

$$
l_{\mathrm{fa}}=\sqrt{\left(r_{1}+r_{2}+\Delta\right)^{2}+\left(x_{\mathrm{v}}+r_{1}+r_{2}\right)^{2}}-\left(r_{1}+r_{2}\right) .
$$

5.2. Gases. At present, the influence of gas pollutant in the hydraulic system is often neglected. The gas is mixed into oil, and it will affect the pressure, viscosity, temperature, and density, but mainly affect the elastic modulus of the oil. The experimental data shows the oil entrains $1 \%$ of gas; the elastic modulus is reduced to $35.6 \%$ of pure oil, which will seriously affect the working performance. The relationship between elastic modulus $K_{\mathrm{e}}$ and gas content of oil is shown as equation (30), from which we find the elastic modulus of oil drops sharply when the gas content increases.

$$
\frac{1}{K_{\mathrm{e}}}=\frac{1}{K_{\mathrm{f}}}+\frac{1}{K_{\mathrm{c}}}+\frac{V_{\mathrm{b}}}{V_{\mathrm{f}} K_{\mathrm{b}}},
$$

where $K_{\mathrm{f}}$ denotes the elastic modulus of gas-free oil; $K_{\mathrm{c}}$ denotes the elastic modulus of hydraulic pipe system; $K_{\mathrm{b}}$ denotes the elastic modulus of gas contained in oil; $V_{\mathrm{b}}$ denotes the volume of gas contained in oil; and $V_{\mathrm{f}}$ denotes the volume of oil and gas mixture. 


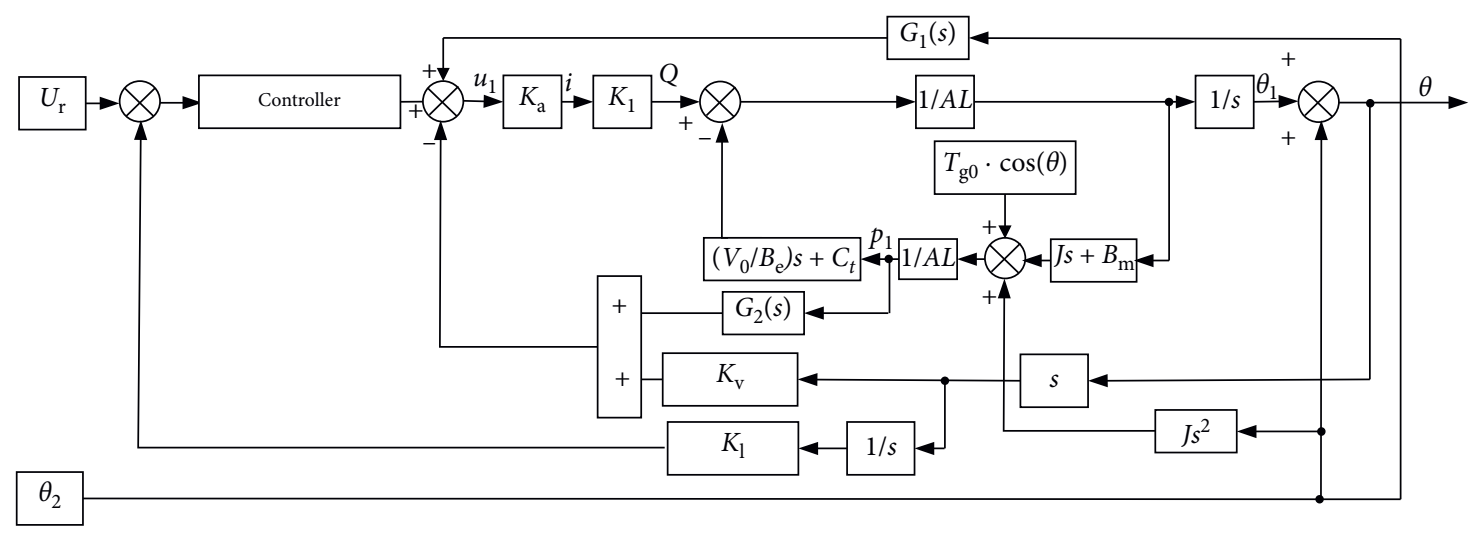

Figure 7: Control diagram of the barrel pitching system.

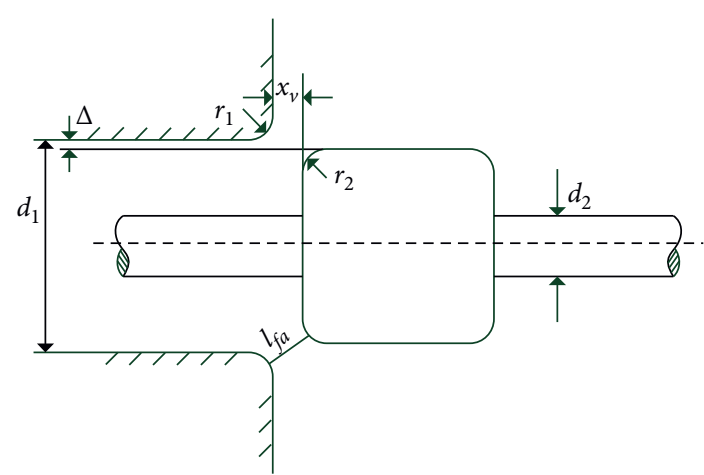

FIgURE 8: The throttle model of spool valve.

5.3. Liquids. The performance parameters will not have significant change when the liquid is mixed into oil alone, but can raise the oil temperature together with solid particles and gases, and the viscosity of oil is closely related to oil temperature. After research, Jiang [10] concluded that the relationship between viscosity and oil temperature satisfies the following empirical equation:

$$
\mu_{x}=\mu_{0} e^{\alpha P-\lambda_{x}\left(t-t_{0}\right)}
$$

where $\mu_{x}$ denotes the viscosity of oil when the pressure is $P$ and the temperature is $t ; \mu_{0}$ denotes the viscosity of oil when the pressure is standard atmospheric pressure and the temperature is $t_{0} ; \alpha$ denotes the viscosity coefficient; and $\lambda_{x}$ denotes the proportional constants of oil to temperature.

According to the analysis result, when the oil temperature changes from $0^{\circ}$ to $150^{\circ}$, the oil viscosity is relatively small, which decreases slowly with the increase of temperature. That is, the oil viscosity will decrease and then lead to the dumping coefficient's decrease of spool core under the action of liquid together with other pollutants.

\section{Fractional Order Fuzzy PID Controller}

In view of the parameters' change induced by oil contamination of barrel pitching system, a fractional order fuzzy PID controller is designed for the control of barrel pitching system. The block diagram of fractional order fuzzy adaptive controller is shown in Figure 9.

\subsection{Fuzzification}

6.1.1. Definition of Variables and Domains. The input variables of the controller are the pitching angle deviation $e$ and the deviation change rate $e_{\mathrm{c}}$, and the output variables are the parameters' correction amount $\Delta k_{p}, \Delta k_{i}$, and $\Delta k_{d}$. The domain of deviation $e$ and deviation change rate $e_{\mathrm{c}}$ are $[-0.5$, $0.5]$ and $[-5,5]$, the domain of $\Delta k_{p}$ is $[-500,500]$, the basic domain of $\Delta k_{i}$ is $[-5,5]$, and the basic domain of $\Delta k_{d}$ is taken as $[-5,5]$. Each variable domain is discretely quantized into 7 levels using NB, NM, NS, ZE, PS, PM, and PB.

6.1.2. Selection of Membership Function. The membership function reflects the relationship between the exact value and the fuzzy value. Both the input and output variables use the triangle membership function.

6.1.3. Fuzzy Rule Base. Based on the knowledge accumulated, the logical relationship between input and output is obtained. Tables 2-4 are the parameter tuning rule bases.

6.2. Fuzzy Inference. The fuzzy reasoning method can be divided into Mamdani reasoning method, Larsen reasoning method, and Zadeh reasoning method. This work selects the most widely used Mamdani reasoning method, and its fuzzy implication relationship is relatively simple, which is obtained by taking the Cartesian product of fuzzy set $\widetilde{A}$ and $\widetilde{B}$.

$$
\mu_{\widetilde{R}_{M}}(x, y)=\mu_{\widetilde{A}}(x) \wedge \mu_{\widetilde{B}}(y) \text {. }
$$

6.3. Defuzzification. Defuzzification is to convert the fuzzy control quantity obtained by fuzzy inference into the exact quantity actually used for control. In this work, the center of gravity method is used to defuzzify.

$$
\Delta k p_{0}=\frac{\sum_{j=1}^{49} \mu_{\Delta k p_{j}} \Delta k p_{j}}{\sum_{j=1}^{49} \mu_{\Delta k p_{j}}},
$$

where $\mu_{\Delta k p j}$ denotes the membership degree of $\Delta k_{p}$ and the exact values of $\Delta k_{i}$ and $\Delta k_{d}$ can be obtained. 


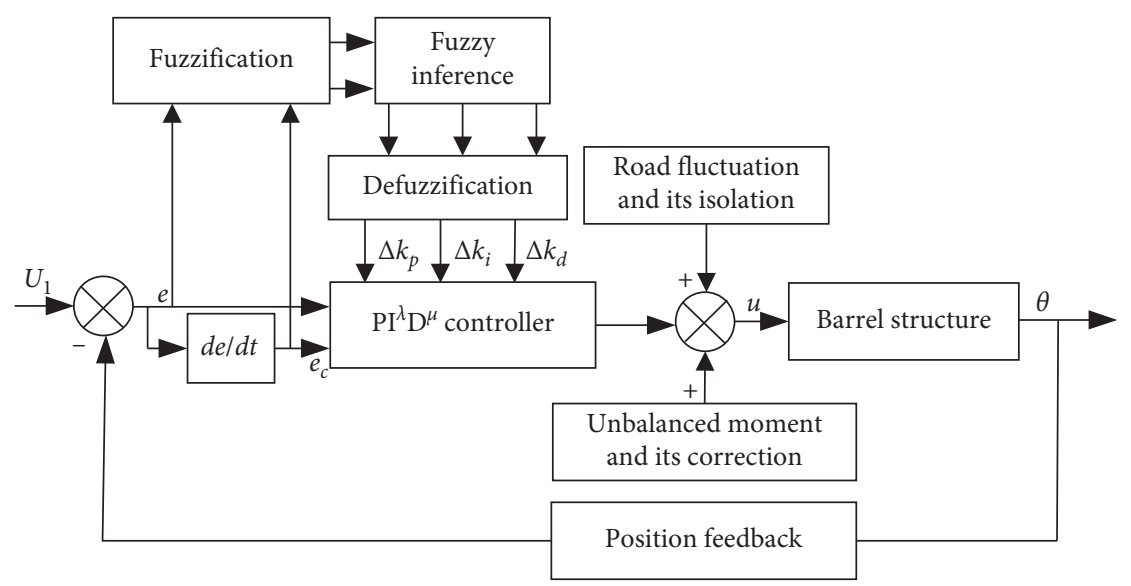

FIgURE 9: Fractional order fuzzy PID structure of the barrel pitching system.

TABle 2: Fuzzy rules of $\Delta k_{p}$.

\begin{tabular}{|c|c|c|c|c|c|c|c|c|}
\hline \multirow{2}{*}{\multicolumn{2}{|c|}{$\Delta k_{p}$}} & \multicolumn{7}{|c|}{$e_{c}$} \\
\hline & & NB & NM & NS & ZE & PS & $\mathrm{PM}$ & $\mathrm{PB}$ \\
\hline \multirow{7}{*}{$e$} & NB & $\mathrm{PB}$ & PB & PM & PM & PS & $\mathrm{ZE}$ & $\mathrm{ZE}$ \\
\hline & NM & $\mathrm{PB}$ & PB & $\mathrm{PM}$ & PS & PS & $\mathrm{ZE}$ & NS \\
\hline & NS & PM & PM & $\mathrm{PM}$ & PS & $\mathrm{ZE}$ & NS & NS \\
\hline & ZE & $\mathrm{PM}$ & PM & PS & ZE & NS & NM & NM \\
\hline & PS & PS & PS & ZE & NS & NS & NM & NM \\
\hline & PM & PS & $\mathrm{ZE}$ & NS & $\mathrm{NM}$ & NS & NM & NM \\
\hline & PB & ZE & ZE & NM & NM & NM & NB & NB \\
\hline
\end{tabular}

TABLE 3: Fuzzy rules of $\Delta k_{i}$.

\begin{tabular}{ccccccccc}
\hline \multicolumn{2}{c}{$\Delta k_{i}$} & & & & $e_{c}$ & & & \\
& & NB & NM & NS & ZE & PS & PM & PB \\
\hline \multirow{6}{*}{$e$} & NB & NB & NB & NM & NM & NS & ZE & ZE \\
& NM & NB & NB & NM & NS & NS & ZE & ZE \\
& NS & NB & NM & NS & NS & ZE & PS & PS \\
& ZE & NM & NM & NS & ZE & PS & PM & PM \\
& PS & NM & NS & ZE & PS & PS & PM & PB \\
& PM & ZE & ZE & PS & PS & PM & PB & PB \\
& PB & ZE & ZE & PS & PM & PM & PB & PB \\
\hline
\end{tabular}

TABLE 4: Fuzzy rules of $\Delta k_{d}$.

\begin{tabular}{|c|c|c|c|c|c|c|c|c|}
\hline \multirow{2}{*}{\multicolumn{2}{|c|}{$\Delta k_{d}$}} & \multicolumn{7}{|c|}{$e_{\mathrm{c}}$} \\
\hline & & NB & NM & NS & ZE & PS & $\mathrm{PM}$ & $\mathrm{PB}$ \\
\hline \multirow{7}{*}{$e$} & NB & PS & NS & $\mathrm{NB}$ & NB & NB & NM & PS \\
\hline & NM & PS & NS & NB & NM & NM & NS & $\mathrm{ZE}$ \\
\hline & NS & $\mathrm{ZE}$ & NS & NM & NM & NS & NS & ZE \\
\hline & ZE & ZE & NS & NS & NS & NS & NS & $\mathrm{ZE}$ \\
\hline & PS & ZE & ZE & ZE & $\mathrm{ZE}$ & ZE & ZE & $\mathrm{ZE}$ \\
\hline & PM & $\mathrm{PB}$ & NS & PS & PS & PS & PS & $\mathrm{PB}$ \\
\hline & PB & $\mathrm{PB}$ & PM & PM & PM & PS & PS & PB \\
\hline
\end{tabular}

\section{Simulation and Discussion}

Based on the given angle signal, the barrel is driven by the electrohydraulic servo system to perform pitching motion, which is detected by the sensor in real time. The PID controller, the fuzzy PID (FPID) controller, and the fractional order fuzzy PID (FOFPID) controller are designed to overcome the influence of unbalanced torque, road 
fluctuation, and oil contamination and finally achieve high precision pitching control of vehicle mounted and unbalanced barrel. The simulation model is built using MATLAB, and the value of simulation parameters is shown in Table 5.

7.1. Simulation of FOFPID Control under Initial Value of Parameters. Based on the FOFPID controller, the barrel pitching angle's step response curve under initial value of parameters is shown in Figure 10, in which the given angle is $0.436\left(25^{\circ}\right) \mathrm{rad}$, and $\lambda$ and $\mu$ are set as 0.78 and 0.84 . As observed, the dynamic response under initial value of parameters has been improved. The FOFPID controller reduces the setting time to $0.2 \mathrm{~s}$. At the same time, the magnified steady state curve is still sine curve instead of straight line, but the magnitude of sine curve and the steady state error are greatly reduced, which is far less than that without control. To summarize, the FOFPID control method can fully satisfy the high precision control requirements under initial unbalanced torque, road fluctuation, and clean oil condition.

7.2. Contrast Simulation under Bigger Unbalanced Torque. Actually, the unbalanced torque $T_{\mathrm{g}}$ will increase because of barrel length's increasing or center of gravity's changing. The bigger unbalanced torque is set as $5000 \mathrm{Nm}$, then the PID controller, the FPID controller, and the FOFPID controller are separately applied to the barrel pitching system, and the contrast simulation curves are shown in Figure 11, from which it is clear to find the dynamic characteristics under FPID is slightly better than the PID's, but the difference is not obvious, and then the FOFPID's is far better than them. Simultaneously, the magnified steady state curves are all sine curves, but the steady state error is $0.000038 \mathrm{rad}$, which is much less than the others; that is, the correction link and the FOFPID control can effectively suppress the influence of unbalanced torque's increase.

7.3. Contrast Simulation under Bigger Magnitude of Road Fluctuation. The magnitude of road fluctuation $\theta_{2}$ will increase because of road level's changing. The bigger unbalanced torque is set as $5^{\circ}(0.087 \mathrm{rad})$, then the PID controller, the FPID controller, and the FOFPID controller are separately applied to the barrel pitching system, and the contrast simulation curves are shown in Figure 12, from which it is clear to find that the dynamic characteristics under FPID is slightly better than the PID's but the difference is not obvious, and then the FOFPID's is far better than them. Simultaneously, the magnified steady state curves are all sine curves, but the steady state error is $0.000132 \mathrm{rad}$, which is less than the others; that is, the pressure difference negative feedback loop and the FOFPID control can effectively suppress the influence of road fluctuation magnitude's increase.

7.4. Contrast Simulation under Bigger Flow Coefficient. The flow coefficient $K_{1}$ will increase because of oil contamination. The bigger flow coefficient is set as $0.131 \mathrm{~m}^{3} /(\mathrm{s} \cdot \mathrm{A})$,
TABLE 5: The parameter value of simulation model.

\begin{tabular}{lc}
\hline Parameter & Value \\
\hline$k_{\mathrm{a}}$ & $0.0012 \mathrm{~A} / \mathrm{V}$ \\
$k_{1}$ & $0.056(0.131) \mathrm{m}^{3} /(\mathrm{s} \cdot \mathrm{A})$ \\
$A$ & $9 e-3 \mathrm{~m}^{2}$ \\
$L$ & $0.314 \mathrm{~m}$ \\
$C_{\mathrm{t}}$ & $1.5 e-13\left(\mathrm{~m}^{3} / \mathrm{s}\right) / \mathrm{Pa}$ \\
$V_{0}$ & $9.735 e-5 \mathrm{~m}^{3}$ \\
$\beta_{\mathrm{e}}$ & $700(100) \mathrm{MPa}$ \\
$B_{\mathrm{m}}$ & $238(20) \mathrm{Nm} /(\mathrm{rad} / \mathrm{s})$ \\
$J$ & $3400 \mathrm{~kg} \cdot \mathrm{m}^{2}$ \\
$k_{1}$ & $1 \mathrm{~V} / \mathrm{rad}$ \\
$k_{\mathrm{v}}$ & $57 \mathrm{~V} /(\mathrm{rad} / \mathrm{s})$ \\
$\theta_{2}$ & $1^{\circ}\left(5^{\circ}\right), 1 \mathrm{~Hz}$ \\
$T_{\mathrm{g} 0}$ & $1000(5000) \mathrm{Nm}$ \\
\hline
\end{tabular}

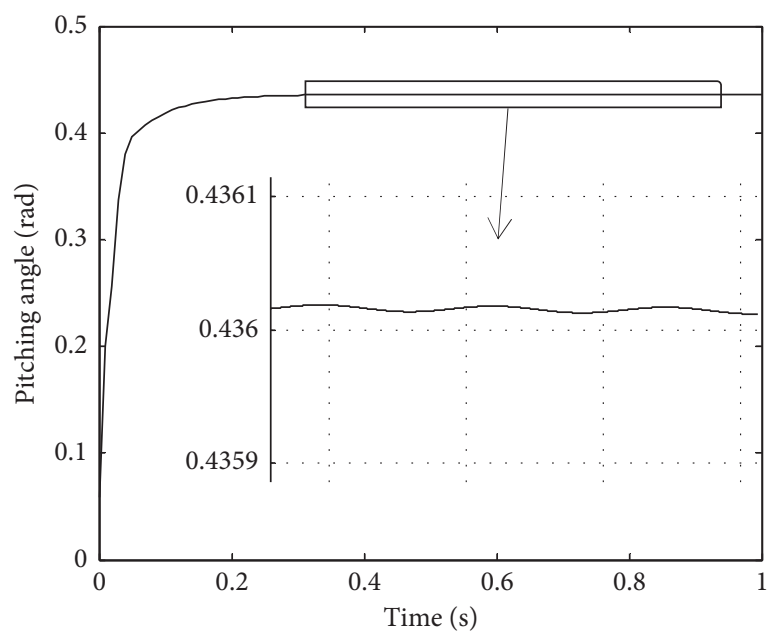

Figure 10: Barrel step response curve.

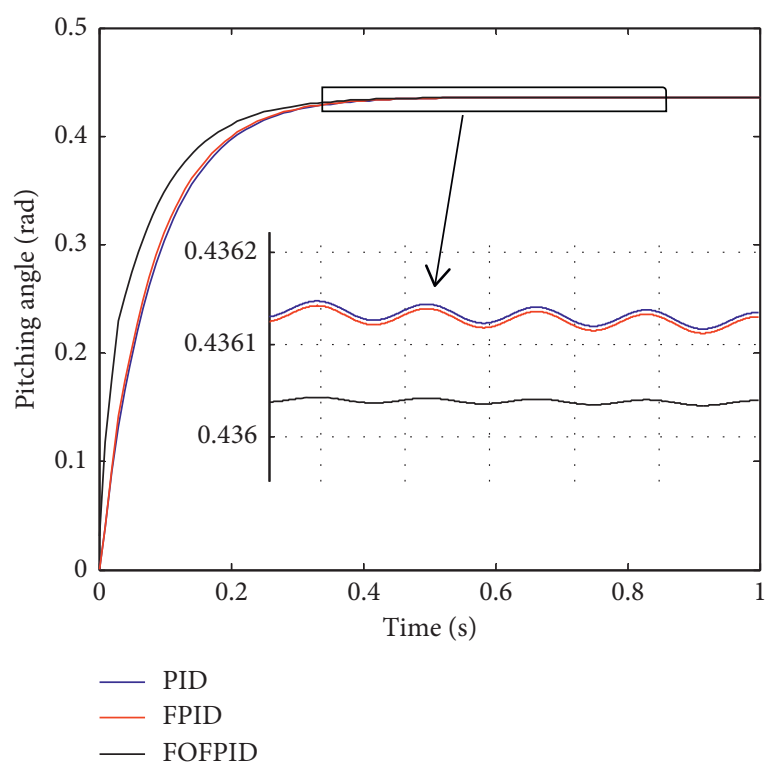

FIgURE 11: Contrast simulation curves under bigger unbalanced torque. 


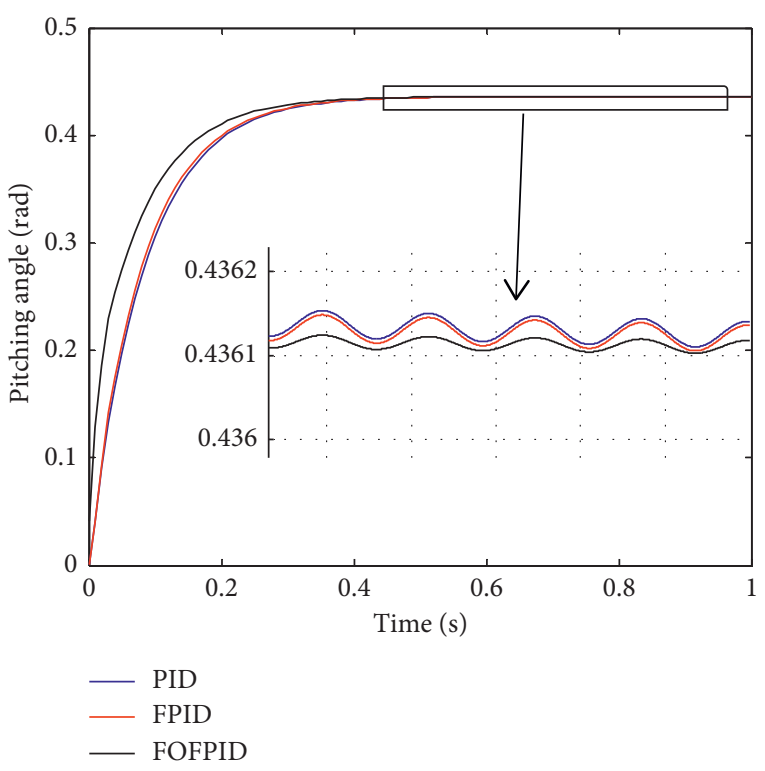

FIGURE 12: Contrast simulation curves under bigger magnitude of road fluctuation.

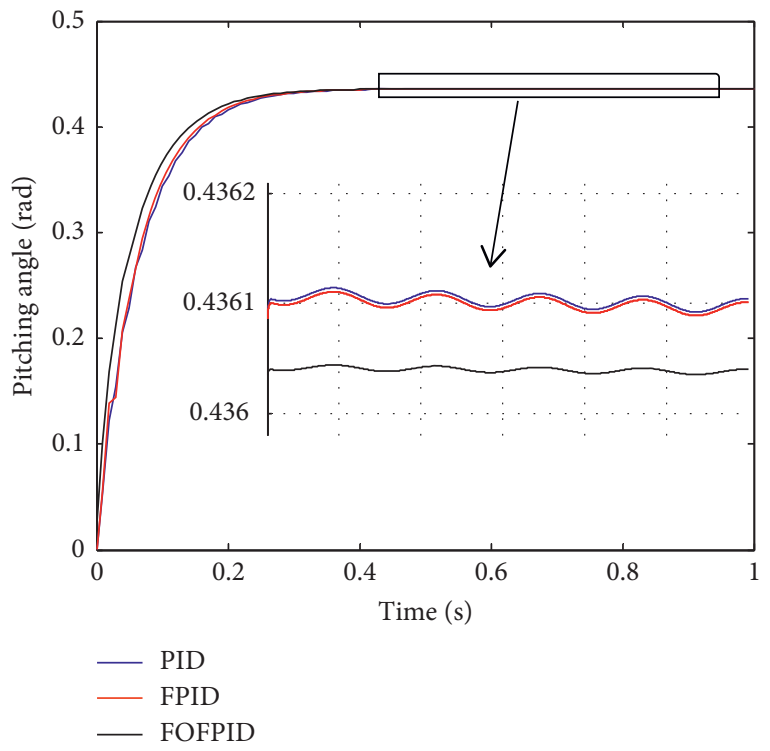

Figure 13: Contrast simulation curves under bigger flow coefficient.

then the PID controller, the FPID controller, and the FOFPID controller are separately applied to the barrel pitching system, and the contrast simulation curves are shown in Figure 13, from which it is clear to find that the dynamic characteristics under FPID is slightly better than the PID's but the difference is not obvious, and then the FOFPID's is far better than them. Simultaneously, the magnified steady state curves are all sine curves, but the steady state error is $0.00003 \mathrm{rad}$, which is much less than the others; that is, the FOFPID control can effectively suppress the influence of flow coefficient's increase.

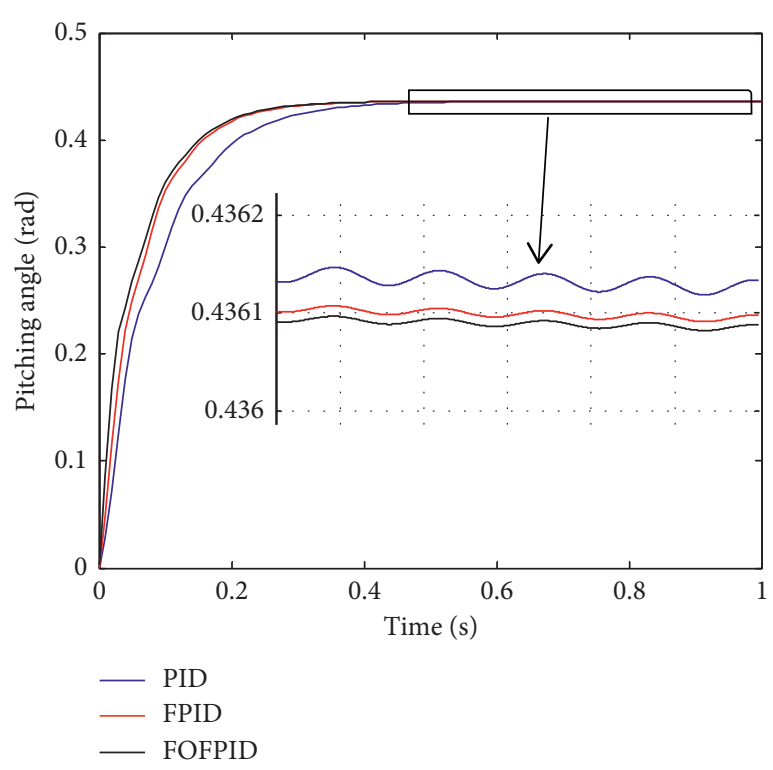

FIgURE 14: Contrast simulation curves under smaller elastic modulus.

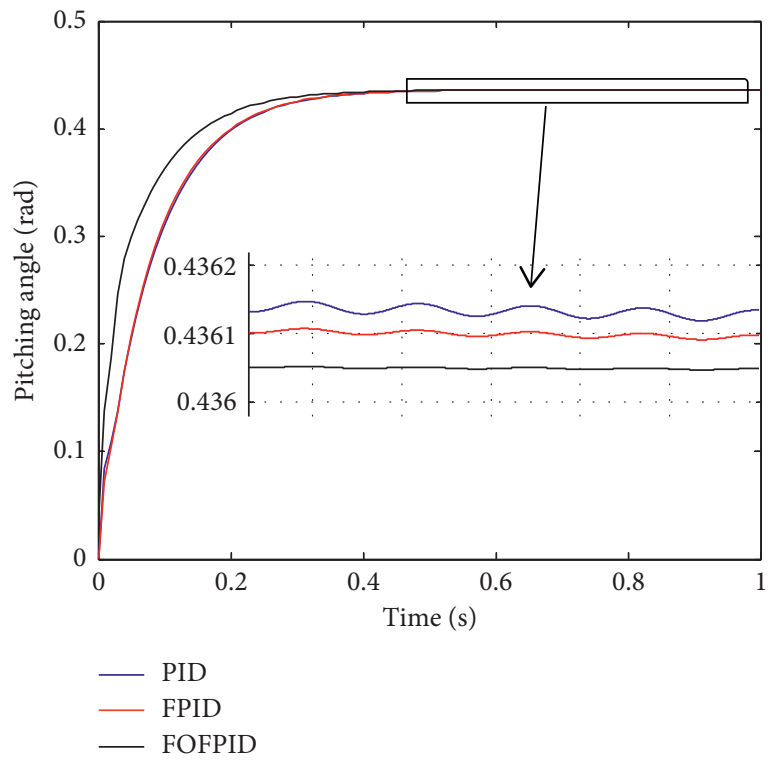

FIgURE 15: Contrast simulation curves under smaller viscosity coefficient.

7.5. Contrast Simulation under Smaller Elastic Modulus. The elastic modulus $\beta_{\mathrm{e}}$ will decrease because of oil contamination. The smaller elastic modulus is set as $100 \mathrm{MPa}$, then the PID controller, the FPID controller, and the FOFPID controller are separately applied to the barrel pitching system, and the contrast simulation curves are shown in Figure 14, from which it is not difficult to find that the dynamic characteristics under FPID is far better than the PID's, and then the FOFPID's is slightly better than the FPID's. Similarly, the FOFPID's steady state performance is 
slightly better than the FPID's but far better than the PID's. Then the steady state error is $0.00009 \mathrm{rad}$; that is, the FOFPID control can effectively suppress the influence of elastic modulus's decrease.

7.6. Contrast Simulation under Smaller Viscosity Coefficient. The viscosity coefficient $B_{\mathrm{m}}$ will decrease because of oil contamination. The smaller viscosity coefficient is set as $20 \mathrm{Nm} /(\mathrm{rad} / \mathrm{s})$, then the PID controller, the FPID controller, and the FOFPID controller are separately applied to the barrel pitching system, and the contrast simulation curves are shown in Figure 15, from which it is clear to find that the dynamic characteristics under FPID is slightly better than the PID's but the difference is not obvious, and then the FOFPID's is far better than them. Simultaneously, the magnified steady state curves are all sine curves, but the steady state error is $0.00005 \mathrm{rad}$, which is much less than the others; that is, the FOFPID control can effectively suppress the influence of viscosity coefficient's decrease.

\section{Conclusions}

In this work, to accomplish the high precision control, the sensitivity analysis of the barrel pitching system is conducted, and the correction link and pressure difference negative feedback loop are respectively designed for suppressing the influence of unbalanced torque and road fluctuation. Also the fractional order fuzzy PID controller has been presented in order to compensate the core parameters' decay induced by the oil contamination and the external interference.

As elaborated, in addition to dynamic characteristic improvement, the setting time is less than $0.2 \mathrm{~s}$. The control method leads to the decrease of steady state error so that the maximum value is $0.000132 \mathrm{rad}$ under external interference and oil contamination conditions. And compared with the PID controller and the fuzzy PID controller, the fractional order fuzzy PID can adjust control parameters in order to adapting to different conditions, so the presented control method is suitable for the control of vehicle mounted and unbalanced barrel pitching system.

Finally, based on the results of this work, an approach for the future research should include the considering of the vehicle vibration's impact on the barrel pitching servo control system.

\section{Data Availability}

The data used to support the findings of this study have not been made available because the data also forms part of an ongoing study.

\section{Conflicts of Interest}

The author declared no potential conflicts of interest with respect to the research, authorship, and/or publication of this article.

\section{Acknowledgments}

This work was supported by the National Natural Science Foundation of China (NSFC) (grant number 51805403), the project supported by Natural Science Basic Research Plan in Shaanxi Province of China (grant number 2019JQ-836), the Natural Science Foundation of Shaanxi Provincial Department of Education (grant number 19JK0416), and the Dean Fund of Photoelectric Institute (grant number 2017GDYJY01).

\section{References}

[1] Y. Q. Xia, L. Dai, M. Y. Fu, C. Li, and C. M. Wang, “Application of active disturbance rejection control in tank gun control system," Journal of the Franklin Institute, vol. 351, no. 4, pp. 2299-2314, 2014.

[2] J. Yao and W. Deng, "Active disturbance rejection adaptive control of hydraulic servo systems," IEEE Transactions on Industrial Electronics, vol. 64, no. 10, pp. 8023-8032, 2017.

[3] G. Yang, J. Yao, G. Le, and D. Ma, "Asymptotic output tracking control of electro-hydraulic systems with unmatched disturbances," IET Control Theory \& Applications, vol. 10, no. 18, pp. 2543-2551, 2016.

[4] K. Li, Q. Gao, J. Gong, and Y. L. Hou, "Modeling and simulation of electro-hydraulic servo system of a certain weapon barrel for balancing and positioning," in Proceedings of the 27th Chinese Control and Decision Conference, pp. 3397-3401, America, Qingdao, China, May 2015.

[5] Q. Gao, Y. L. Hou, K. Li, Z. Sun, C. Wang, and R. Hou, "Neural network based active disturbance rejection control of a novel electro-hydraulic servo system for simultaneously balancing and positioning by isoactuation configuration," Shock and Vibration, vol. 2016, Article ID 4921095, 9 pages, 2016.

[6] E. L. Zhao, "Analysing dynamics mathematics model of cannon stable system and the system stable precision," Fire Control and Command Control, vol. 28, no. 6, pp. 51-54, 2003.

[7] R.-C. Zhang, X. Yu, Y.-L. Hu, H.-J. Zang, and W. Shu, "Active control of hydraulic oil contamination to extend the service life of aviation hydraulic system," The International Journal of Advanced Manufacturing Technology, vol. 96, no. 5-8, pp. 1693-1704, 2018.

[8] X. Kong, B. Yu, and L. X. Quan, “Trajectory sensitivity analysis of hydraulic drive unit of quadruped bionic robot," Journal of Mechanical Engineering, vol. 49, no. 14, pp. 170-175, 2013.

[9] Y. Li, S. Wang, M. M. Tomovic, and C. Zhang, "Erosion degradation characteristics of a linear electro-hydrostatic actuator under a high-frequency turbulent flow field," Chinese Journal of Aeronautics, vol. 31, no. 5, pp. 914-926, 2018.

[10] S. Q. Jiang, "Thermal characteristic study on the friction force of the hydraulic servo spool valve," Master thesis, Beijing Jiaotong University, Beijing, China, 2016. 


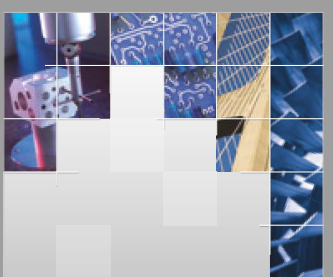

\section{Enfincering}
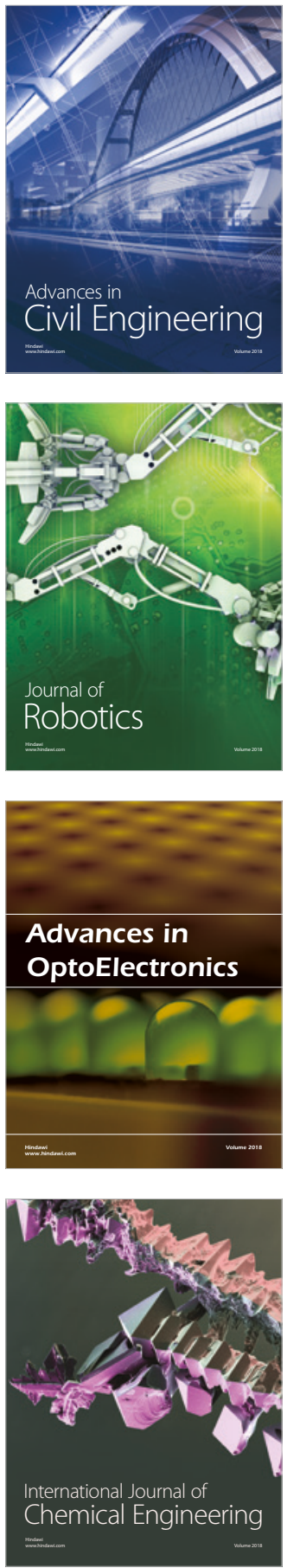

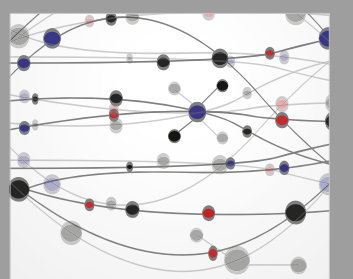

\section{Rotating \\ Machinery}

The Scientific World Journal

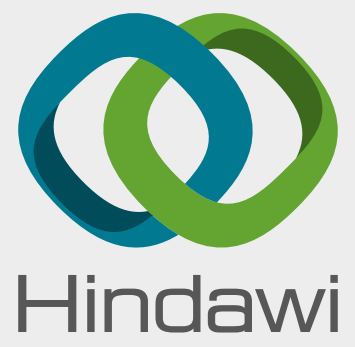

Submit your manuscripts at

www.hindawi.com
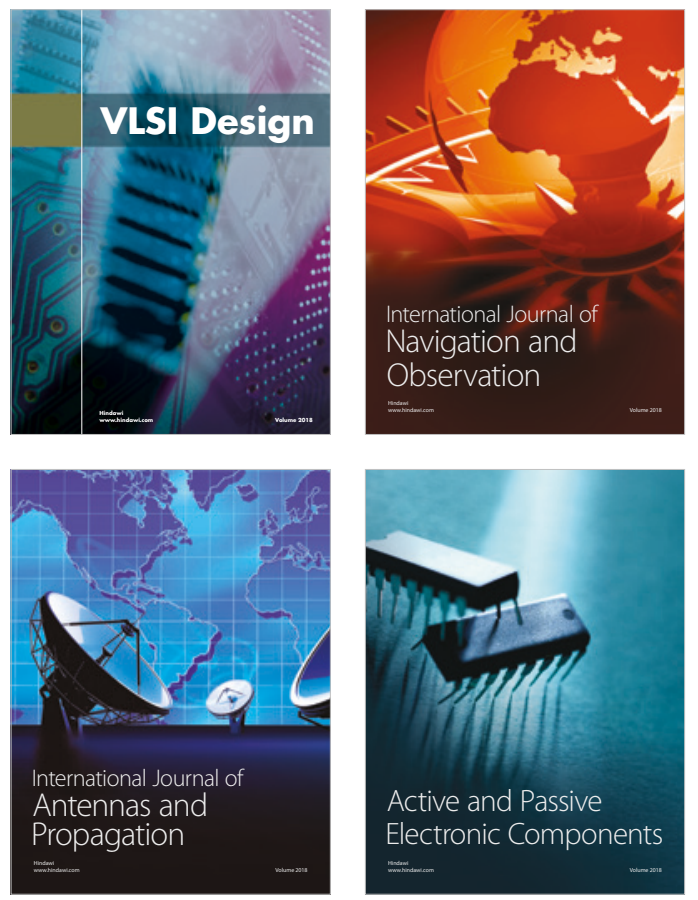
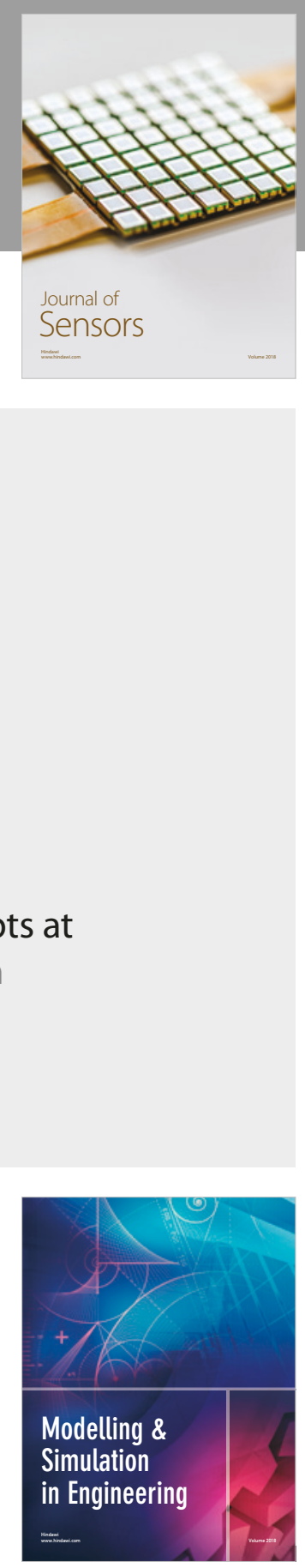

\section{Advances \\ Multimedia}
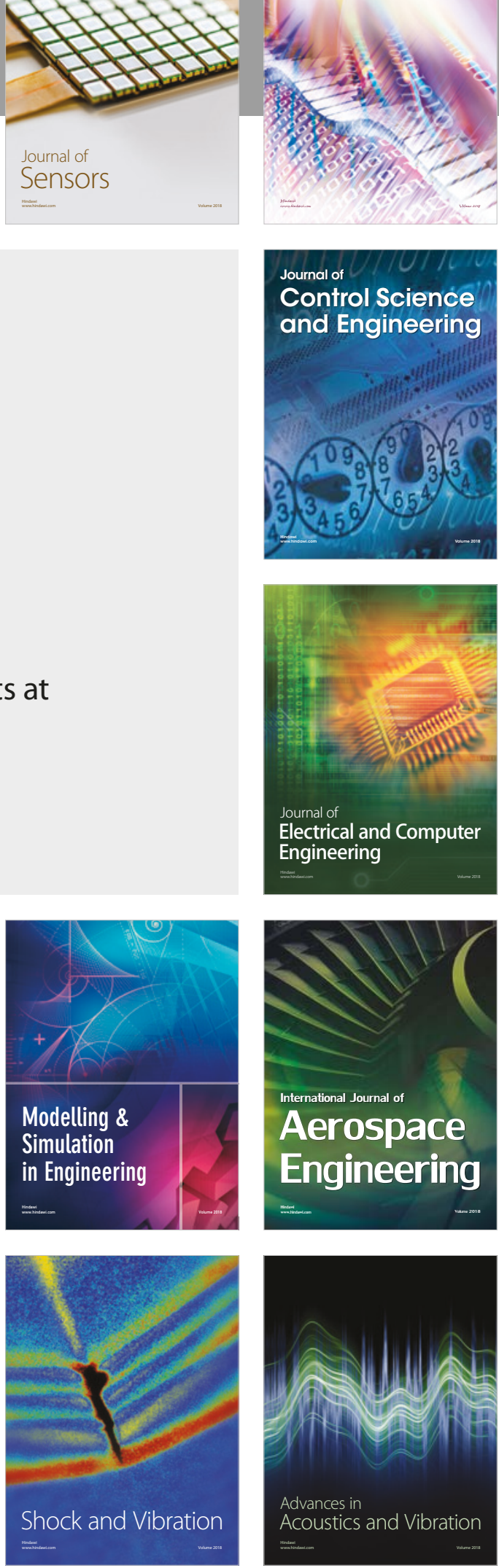